\title{
How should I treat multiple coronary aneurysms with severe stenoses?
}

\author{
Takayuki Warisawa ${ }^{1}$, MD; Toru Naganuma ${ }^{1}$, MD, FACC, FESC; \\ Sunao Nakamura ${ }^{1 *}, \mathrm{MD}, \mathrm{PhD}, \mathrm{FACC}$, FAHA, FESC, FSCAI \\ Department of Cardiovascular Medicine, New Tokyo Hospital, Chiba, Japan
}

\begin{abstract}
Invited experts: Marc Hartmann ${ }^{l}$, MD, PhD; Martin G. Stoel ${ }^{l}$, MD, PhD; J. (Hans) W. Louwerenburg ${ }^{l}$, MD; Mounir W.Z. Basalus ${ }^{1}$, MD, PhD, Clemens von Birgelen ${ }^{1,2}, \mathrm{MD}, \mathrm{PhD}$; Bon-Kwon $\mathrm{Koo}^{3}, \mathrm{MD}, \mathrm{PhD}$

1. Department of Cardiology, Thoraxcentrum Twente, Medisch Spectrum Twente, Enschede, The Netherlands; 2. Department of Health Technology and Services Research, MIRA - Institute for Biomedical Technology and Technical Medicine, University of Twente, Enschede, The Netherlands; 3. Department of Internal Medicine, Cardiovascular Center, Seoul National University Hospital, Seoul, South Korea
\end{abstract}

The concluding section "How did I treat?" together with the complete references and the accompanying supplementary data are published online at: http://www.pcronline.com/eurointervention/90th_issue/171

\section{CASE SUMMARY}

BACKGROUND: A 46-year-old male, with a history of old myocardial infarction in the first diagonal branch (D1) treated with balloon angioplasty three years before, was admitted to our institution because of chest pain on effort. He underwent coronary angiography which revealed multiple coronary aneurysms in the left anterior descending artery (LAD) and the D1 with severe stenoses in the LAD, $\mathrm{D} 1$, and the obtuse marginal branch.

INVESTIGATION: Coronary angiography, fractional flow reserve, scintigraphy, coronary computed tomography.

DIAGNOSIS: Multiple coronary aneurysms with severe stenoses.

MANAGEMENT: Percutaneous coil embolisation and stenting.

KEYWORDS: aneurysm, coil embolisation, polytetrafluoroethylene-covered stent

\section{PRESENTATION OF THE CASE}

A 46-year-old male, with a history of old myocardial infarction (MI) in the first diagonal branch (D1) treated with balloon angioplasty three years before, was admitted to our institution because of chest pain on effort. Coronary angiography revealed coronary artery aneurysms measuring approximately $10 \mathrm{~mm}$ and $7 \mathrm{~mm}$ in the left anterior descending artery (LAD) and D1, respectively (Figure 1A), which were not clearly detected three years before. Moreover, significant stenoses were also demonstrated proximal to both aneurysms, distal to the D1 aneurysm, and in the obtuse marginal (OM) branch (Figure 1A, Figure 1B). The fractional flow reserve (FFR) in the LAD was 0.50, as measured with PressureWire ${ }^{\mathrm{TM}}$, Certus ${ }^{\mathrm{TM}}$ (St. Jude Medical, St. Paul, MN, USA) (Figure 1C). Electrocardiography showed a Q-wave in I, aVL, which indicated transmural MI in the D1 region (Figure 2A). Echocardiography showed thinness of the wall with akinetic motion in the anterolateral left ventricular wall. The left ventricular ejection fraction was $53 \%$ and there was no valvular pathology. 201Tl-123I-BMIPP scintigraphy demonstrated no viability in the D1 region (Figure 2B). Coronary angiography (Figure 2C) was performed in approximately the same view as the coronary computed tomography (Figure 2D) to be easily compared. Reststress myocardial perfusion scintigraphy showed ischaemia in the LAD and OM regions, and transmural MI in the D1 region. The fusion image of coronary computed tomography and scintigraphy

\footnotetext{
*Corresponding author: New Tokyo Hospital, 1271 Wanagaya, Matsudo, Chiba, 270-2232, Japan. E-mail: boss0606@pluto.plala.or.jp
} 
confirmed the above-mentioned anatomical and physiological information much more clearly (Figure 2D). As the patient and his family refused a surgical operation, percutaneous coronary intervention (PCI) was planned.

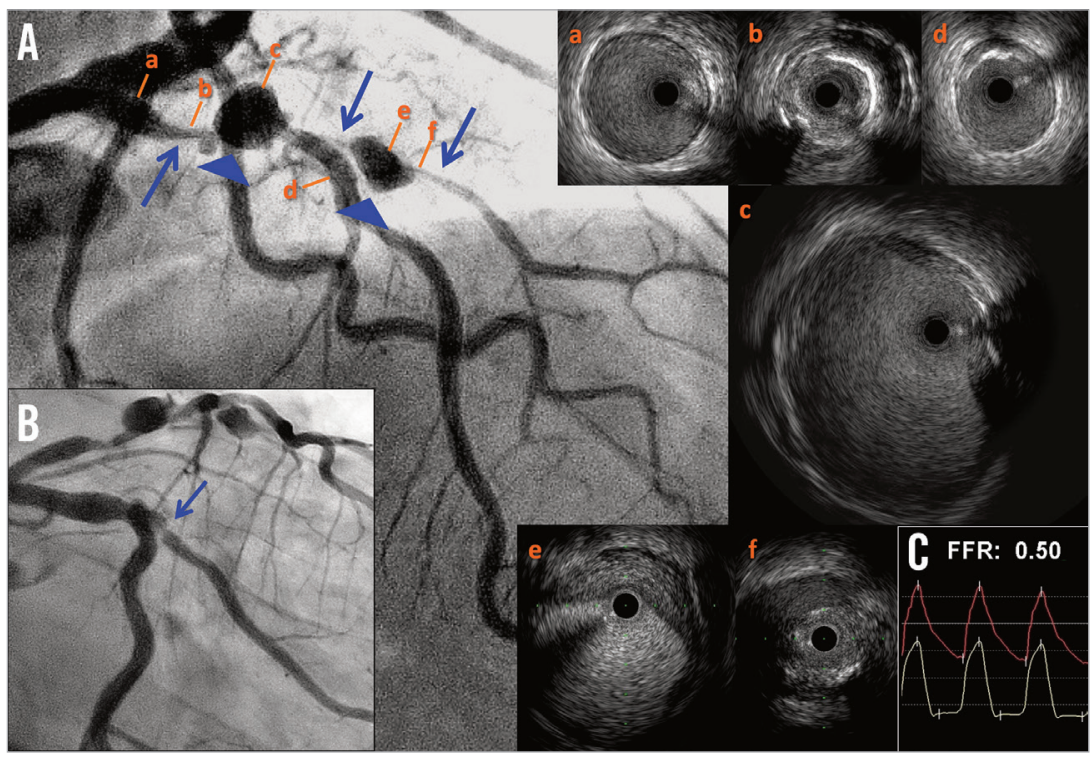

Figure 1. Coronary angiography and intravascular ultrasound (IVUS) images. A) The cranial view revealed severe stenoses (blue arrows) and aneurysms (blue arrowheads) both in the left anterior descending artery (LAD) and in the first diagonal branch (D1). a) Proximal LAD reference: $4.0 \times 3.5 \mathrm{~mm}$. b) The LAD minimum lumen with an eccentric calcified lesion. Minimum lumen area (MLA): $\left.2.4 \mathrm{~mm} \mathrm{~m}^{2} . c\right)$ The LAD aneurysm: $10.2 \times 8.7 \mathrm{~mm}$. d) Distal LAD reference: $3.2 \times 3.1 \mathrm{~mm}$. e) The D1 aneurysm: $6.9 \times 6.0 \mathrm{~mm}$. f) The D1 minimum lumen.

MLA: $0.47 \mathrm{~mm}^{2}$. B) The caudal view revealed severe stenosis in the obtuse marginal branch (OM; blue arrow). C) The fractional flow reserve (FFR) in the LAD under maximal hyperaemia with adenosine was 0.50.

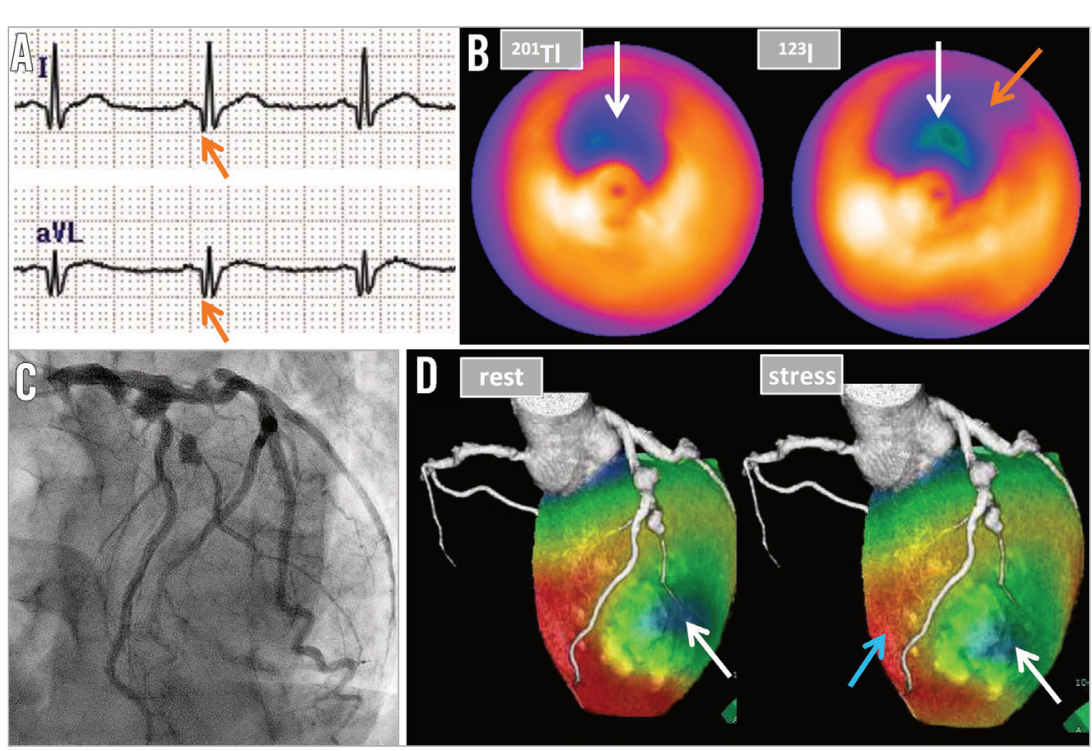

Figure 2. Physiological assessments of ischaemia. A) Electrocardiography showed a Q-wave in I, aVL (orange arrows), which indicated transmural myocardial infarction in the first diagonal branch (D1) region. B) 201Tl-123I-BMIPP scintigraphy demonstrated decreased uptake of both thallium-201 and iodine-123- $\beta$-methyl iodophenyl-pentadecanoic acid in the D1 region (white arrows), which indicated no viability of the myocardium in this region. It also showed decreased uptake of 123I-BMIPP alone in the obtuse marginal (OM) branch region, which indicated significant ischaemia in this region (orange arrow). C) Coronary angiography in the left anterior oblique cranial view.

D) The fusion image of coronary computed tomography and rest-stress myocardial perfusion scintigraphy visualised ischaemia in the left anterior descending artery (LAD) region (light blue arrow) in the stress condition with intravenous injection of adenosine at 120 pg/kg/min for six minutes. The image also revealed transmural myocardial infarction in the D1 region (white arrows). 


\title{
How would I treat?
}

\section{THE INVITED EXPERTS' OPINION}

\author{
Marc Hartmann ${ }^{1}, \mathrm{MD}, \mathrm{PhD}$; Martin G. Stoel ${ }^{1}, \mathrm{MD}, \mathrm{PhD}$; J. (Hans) W. Louwerenburg ${ }^{1}$, MD; \\ Mounir W.Z. Basalus ${ }^{1}$, MD, PhD; Clemens von Birgelen ${ }^{1,2 *}$, MD PhD
}

1. Department of Cardiology, Thoraxcentrum Twente, Medisch Spectrum Twente, Enschede, The Netherlands; 2. Department of Health Technology and Services Research, MIRA - Institute for Biomedical Technology and Technical Medicine, University of

Twente, Enschede, The Netherlands

The authors present the case of a patient with significant stenoses and aneurysm formation in the LAD and a severe OM stenosis. The stenotic D1 branch, which also shows an aneurysm, subtends nonviable myocardium. Based on the information provided, we must assume that the aneurysms developed or significantly enlarged during the last three years. Coronary aneurysms can develop in the presence of atherosclerosis, but other causes should be considered, such as systemic inflammatory and autoimmune diseases ${ }^{1}$, collagenoses, and thoracic or PCI-related traumas. The latter might have caused the D1 aneurysm. While we consider surgical treatment a valuable option, the patient refused it.

Therefore, we would proceed to PCI and treat the short OM lesion with a drug-eluting stent (DES). Then we would address the LAD, while the D1 does not require specific treatment, as it subtends infarcted myocardium.

The LAD lesions should be adequately predilated, and then there are two treatment options.

Option A (preferred) would be to treat the LAD lesions and the aneurysm with a polytetrafluoroethylene (PTFE)-covered stent graft. A description of such a procedure with a commercially available PTFE-covered stent graft was first published in $1998^{2}$. It would exclude the aneurysm from the coronary artery lumen and prevent potential further growth and the risk of rupture, thrombus formation and distal embolisation ${ }^{2,3}$. In addition, the D1 would be excluded. First-generation PTFE-covered stent grafts consisted of two layers of stainless steel stents, which explains the high rates of restenosis and stent thrombosis (the latter also due to delayed healing) which prevented an unrestricted use $\mathrm{e}^{4-6}$. Nowadays, flexible devices are available that have a relatively low crossing profile due to the use of a single stent layer, to which a PTFE or pericardial membrane is attached ${ }^{7}$. Because of the low frequency of use, reliable restenosis data are scarce. It is uncertain whether treatment with DES plus a membrane-covered stent graft may be useful, as it could avoid restenosis but might increase the stent thrombosis risk $^{8}$. Nevertheless, if the latter approach is chosen, DES should generously cover the proximal and distal reference segments (outside the stent graft), and prolonged dual antiplatelet therapy should be considered.

Option B would be to treat the LAD lesions proximal and distal to the aneurysm with DES of an appropriate length but leave the aneurysm uncovered. During follow-up, we would then recommend an invasive or non-invasive (e.g., coronary computed tomography angiography) assessment of aneurysm size.

\section{Conflict of interest statement}

C. von Birgelen is a consultant to Boston Scientific and Medtronic and has received lecture fees from AstraZeneca. The other authors have no conflicts of interest to declare. 


\title{
How would I treat?
}

\section{THE INVITED EXPERT'S OPINION}

\author{
Bon-Kwon Koo*, MD, PhD
}

Department of Internal Medicine, Cardiovascular Center, Seoul National University Hospital, Seoul, South Korea

T. Warisawa and colleagues present a very interesting, but complicated case. A 46-year-old male who had an MI three years ago now presents with angina pectoris, and with multiple coronary stenoses and aneurysms. The patient and his family refused surgical correction; therefore, PCI was planned. As an interventional cardiologist, I believe three questions need to be addressed regarding PCI for this patient.

\section{How to relieve ischaemia?}

Simple stent implantation for the LAD and OM branch seems sufficient to relieve the myocardial ischaemia and the patient's symptoms. Revascularisation for D1 is not indicated since there is no evidence of reversible ischaemia. The choice between a bare metal and drug-eluting stent should be made according to the patient's general condition.

\section{How to treat the aneurysm?}

Although there is no consensus on the optimal treatment strategy for coronary artery aneurysms, those in the LAD and D1 may need invasive treatment due to their size and development over the last three years. One option could be to use a PTFE-covered stent to exclude both the LAD aneurysm and D $1^{9}$. However, considering the long distance from the LAD ostium to the large first septal branch, there is a risk of myocardial injury due to the occlusion of several small septal branches by a covered stent. In addition, as the D1 supplies a large myocardial territory, the risk of D1 exclusion with a covered stent needs to be evaluated before the procedure. Furthermore, if this branch is connected with high collateral flow, simple obliteration of antegrade flow may not be enough to treat the aneurysm.
In this situation, assessment of symptoms, electrocardiogram (ECG) changes and measurement of distal coronary pressure (coronary wedge pressure) during transient antegrade flow occlusion can be helpful ${ }^{10}$. If careful angiographic evaluation reveals no significant septal branches at the segment of covered stent implantation, and balloon occlusion of the D1 is not associated with clinical and electrical changes and the coronary wedge pressure is not high, implantation of a covered stent can be a treatment option. If not, stent-assisted coil embolisation can be tried after careful discussion with the patient and his family regarding potential risk, benefits, and other alternative options ${ }^{11,12}$.

\section{How to treat the patient?}

The last, but maybe the most important, question is how to treat this patient. It is uncommon to have a patient at the age of 46 presenting with rapidly growing multiple coronary aneurysms. As the aneurysms occurred in injured as well as non-injured coronary segments and the proximal left circumflex artery seems to be ectatic, systemic disease which can be associated with multiple arterial aneurysms should be thoroughly investigated ${ }^{13-15}$. Local treatment for systemic disease may not be sufficient to treat the patient's underlying problem fully.

In summary, before PCI, the patient's possible underlying disease should be thoroughly investigated. Then, the aneurysm and stenosis can be treated by either a PTFE-covered stent ( \pm conventional stent) or stent-assisted coil embolisation, according to the results of further assessment. In any case, the decision should be made after thoughtful discussion with the surgeons, the patient and his family.

\section{Conflict of interest statement}

The author has no conflicts of interest to declare. 


\section{How did I treat?}

\section{ACTUAL TREATMENT AND MANAGEMENT OF THE CASE}

Transfemoral PCI was performed with a 7 Fr guiding catheter. After standard heparinisation, two IDC ${ }^{\text {TM }}$ (interlocking detachable coils) of $2.0 \times 40 \mathrm{~mm}$ (Boston Scientific, Marlborough, MA, USA) were released at the distal D1 through a microcatheter (Renegade ${ }^{\mathrm{TM}}$; Boston Scientific) (Moving image 1). Subsequently, an additional IDCTM of $5.0 \times 120 \mathrm{~mm}$ was successfully released and packed into the aneurysm (Figure $3 \mathrm{~A}$ ). A significant decrease of blood flow in the D1 occurred (TIMI 1) (Figure 3B). Then, a $2.75 \times 13 \mathrm{~mm}$ scoring balloon was used to dilate the proximal LAD lesion according to the intravascular ultrasound (IVUS) findings, which included severe calcification. After a $2.8 \times 26 \mathrm{~mm}$ polytetrafluoroethylene (PTFE)-covered stent (JOSTENT GRAFTMASTER ${ }^{\circledR}$; Abbott Vascular, Santa Clara, CA, USA) had been deployed across the orifice of the D1 (Figure 3C), blood flow from LAD into D1 disappeared completely (TIMI 0 ). Post-dilatation was performed with a $3.5 \times 8 \mathrm{~mm}$ non-compliant balloon at high pressure according to IVUS findings. Eventually, TIMI 3 flow and elimination of the LAD aneurysm were achieved (Figure 4A, Moving image 2). Good stent apposition and preserved lumen area were confirmed both by IVUS and by optical coherence tomography (OCT) (Figure 4B, Figure 4C). Post-procedural FFR in the LAD improved significantly (to 0.90) (Figure 4D). The maximum creatine kinaseMB level in plasma after the procedure was elevated, only up to $39 \mathrm{U} / \mathrm{L}$. The patient was discharged three days after the procedure. One month later, the remaining OM lesion was also treated with a drug-eluting stent.

Three months after the treatment of the aneurysms, follow-up rest-stress myocardial perfusion scintigraphy showed remarkable reduction of the ischaemia in both the LAD and OM regions (Figure 5A). Coronary computed tomography showed no blood flow in the D1 and the absence of recurrent aneurysms in the LAD. The fusion image of scintigraphy and coronary computed tomography was also excellent (Figure 5B).

\section{Discussion}

The optimal strategy against a coronary artery aneurysm (CAA) is controversial, and evidence-based treatment guidelines are not available. The strategy options include PCI, bypass surgery and conservative therapy with antiplatelet and/or anticoagulant medication $^{16}$. Although the natural history of the CAA is unclear, the prognosis of coronary artery stenosis with a CAA is known to be worse than that of stenosis alone ${ }^{17}$. In addition, one study on FFR suggested that a CAA may cause additional ischaemia accompanied by stenosis ${ }^{18}$. This holds true also in the present case: myocardial ischaemia caused by severe stenoses with CAAs. PCI indication for the LAD may be justified based on the fact that the estimated ischaemic burden in this segment was $\geq 10 \%{ }^{19}$.

Multiple physiological tests demonstrated severe ischaemia in the LAD and OM regions with no viability in the D1 region. Furthermore, both CAAs carried a rupture risk because they were expanding. This fact indicated that revascularisation of the LAD and $\mathrm{OM}$ and elimination of both CAAs were necessary, and occlusion of the D1 was acceptable.

The key point for invasive therapy of a CAA is to inhibit both inflow and outflow. As a small collateral artery from the distal LAD to the distal D1 was found, coils were packed not only into the
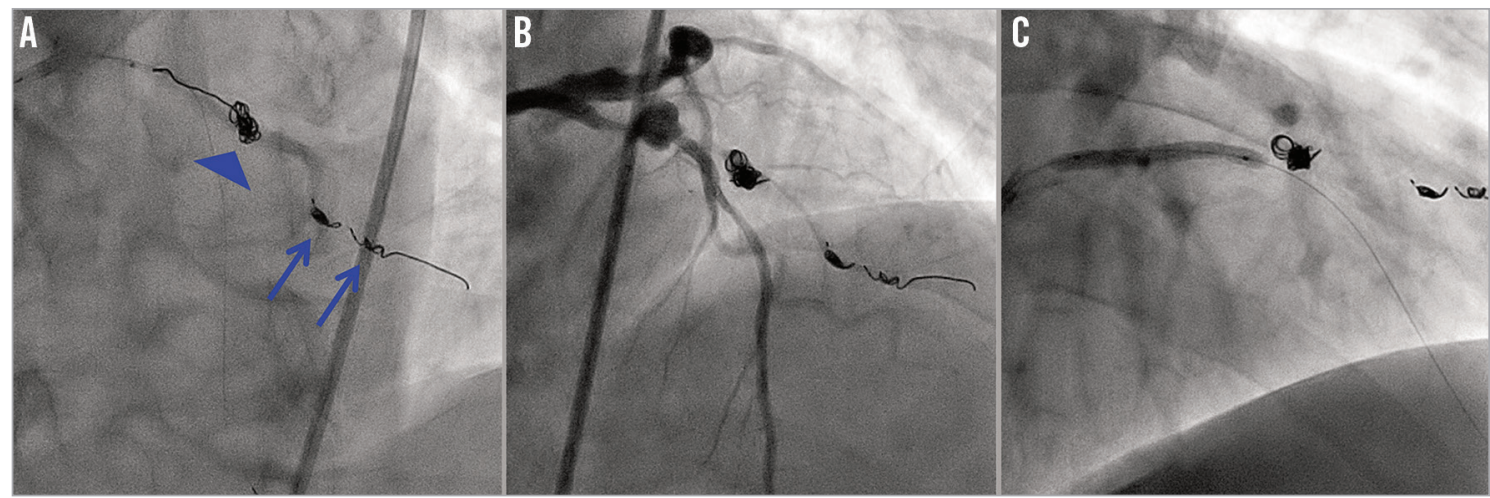

Figure 3. Percutaneous coronary intervention. A) Advancement of the third coil into the first diagonal branch aneurysm through the microcatheter (blue arrowhead) after two coil embolisations in the distal portion of the aneurysm (blue arrows). B) TIMI 1 flow was confirmed after the coil embolisation procedure. C) A polytetrafluoroethylene-covered stent was deployed in the stenotic lesion with an aneurysm in the left anterior descending artery. 

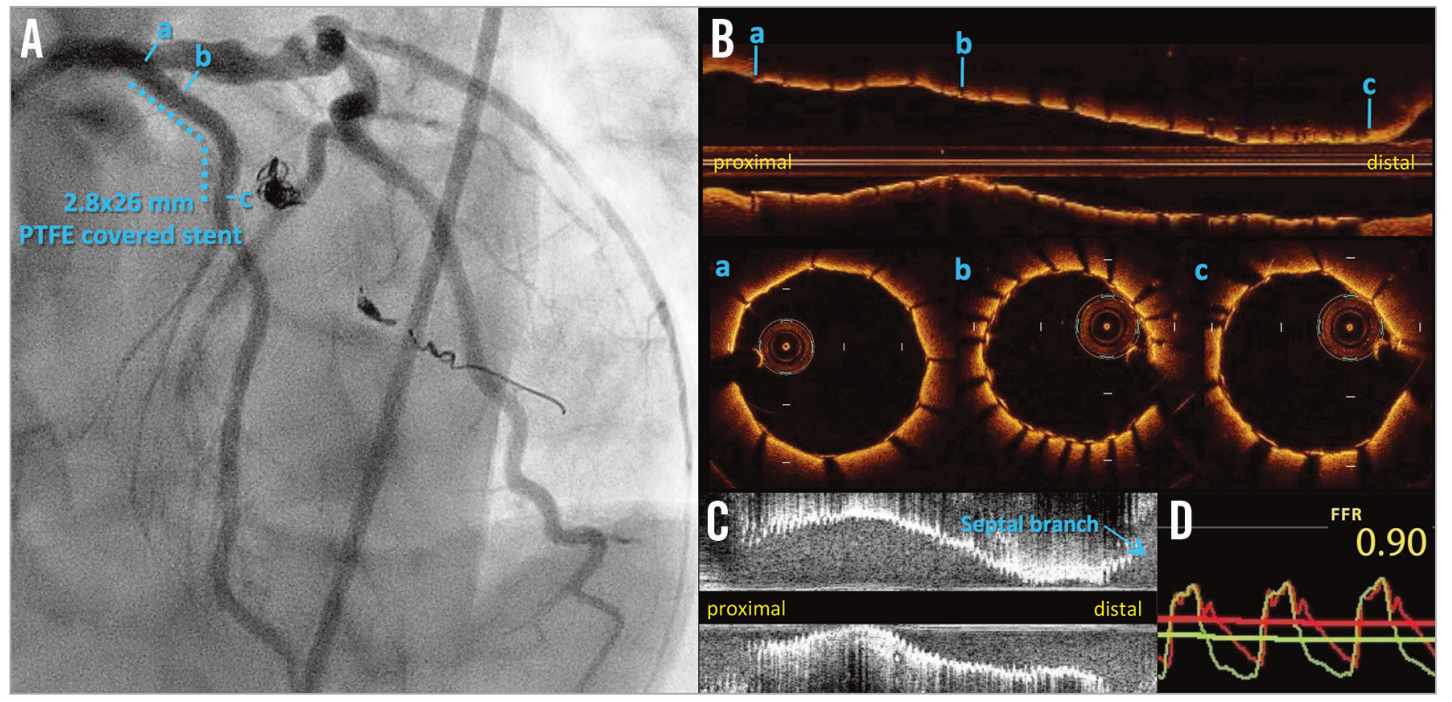

Figure 4. Final angiography and findings of invasive tests. A) TIMI 3 flow and elimination of the aneurysm in the left anterior descending artery (LAD) were achieved, while blood flow into the first diagonal branch disappeared completely. B) A longitudinal image of optical coherence tomography demonstrated a well-apposed stent with an adequate stent area. a) Good stent apposition at the proximal edge. b) The minimum stent area: $5.21 \mathrm{~mm}^{2}$. c) Good stent apposition at the distal edge. C) A longitudinal image of intravascular ultrasound demonstrated a well-apposed stent with an adequate stent area (minimum stent area: $5.65 \mathrm{~mm}^{2}$ ). D) The fractional flow reserve in the LAD after the whole percutaneous coronary intervention procedure improved from 0.50 to 0.90 .

aneurysm but also at the distal portion of the D1. For inhibition of inflow to the D1 aneurysm and for sealing off the LAD aneurysm, a PTFE-covered stent is believed to be more effective than a conventional metallic stent ${ }^{16}$. Optimal stenting with imaging guidance using IVUS and/or OCT is also necessary to prevent an aneurysm from recurring.

To the best of our knowledge, this is the first case report showing that multiple coronary artery aneurysms with severe stenoses can be successfully treated with the combination of coil embolisation and a covered stent based on multiple physiological assessments.

\section{Conflict of interest statement}

The authors have no conflicts of interest to declare.

\section{References}

1. Hartmann M, Wajon EM, van Houwelingen GK, Stoel MG, von Birgelen C. Giant coronary aneurysm in Churg-Strauss syndrome. EuroIntervention. 2012;8:760-1.

2. von Birgelen C, Haude M, Liu F, Ge J, Görge G, Welge D, Wieneke H, Baumgart D, Opherk D, Erbel R. Treatment of coronary pseudoaneurysm by stent-graft implantation. Dtsch Med Wochenschr. 1998;123:418-22.

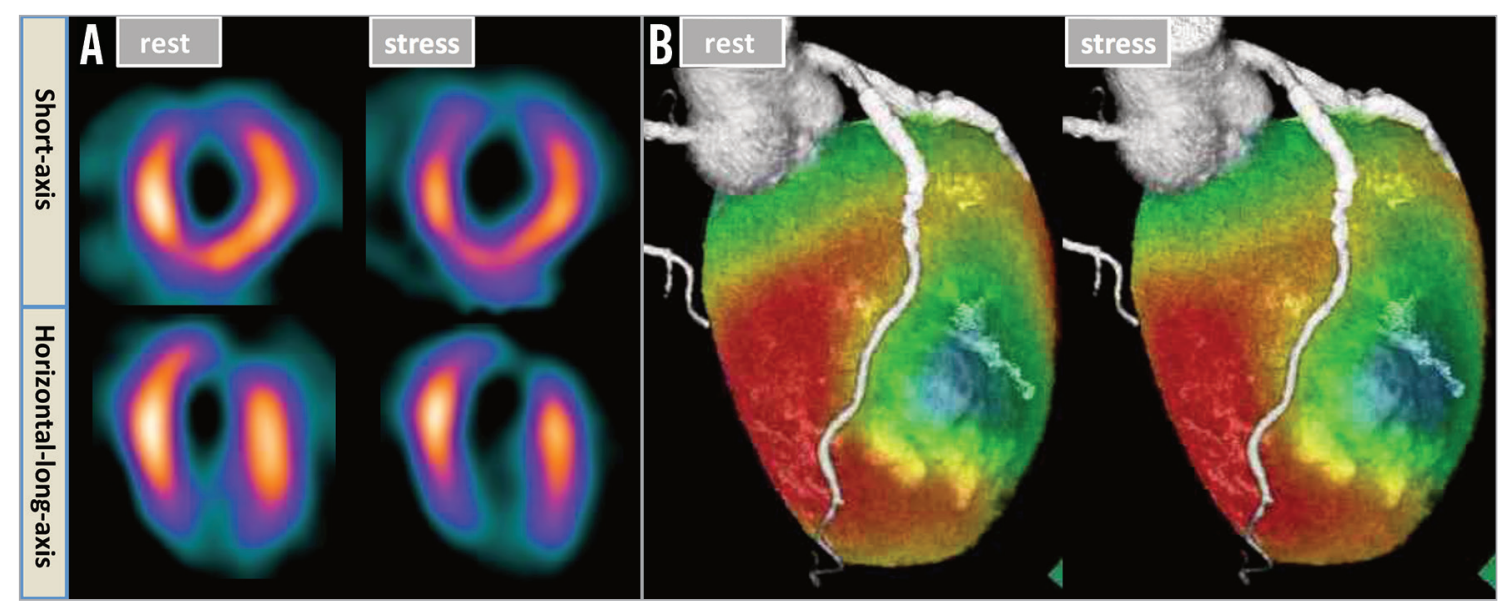

Figure 5. Follow-up anatomical and physiological assessments. A) Rest-stress myocardial perfusion scintigraphy showed little residual ischaemia in the left anterior descending artery (LAD) and obtuse marginal (OM) branch regions. B) The absence of blood flow in the first diagonal branch (D1) and recurrent aneurysms in the LAD, with transmural myocardial infarction in the D1 region and no ischaemia in the $L A D$ region, were confirmed by means of a fusion image of scintigraphy and coronary computed tomography. 
3. von Birgelen $\mathrm{C}$, Haude $\mathrm{M}$, Herrmann J, Altmann C, Klinkhart W, Welge D, Wieneke H, Baumgart D, Sack S, Erbel R. Early clinical experience with the implantation of a novel synthetic coronary stent graft. Catheter Cardiovasc Interv. 1999;47:496-503.

4. Gercken U, Lansky AJ, Buellesfeld L, Desai K, Badereldin M, Mueller R, Selbach G, Leon MB, Grube E. Results of the Jostent coronary stent graft implantation in various clinical settings: procedural and follow-up results. Catheter Cardiovasc Interv. 2002;56:353-60.

5. Takano M, Yamamoto M, Inami T, Murakami D, Seino Y, Mizuno K. Delayed healing of a coronary stent graft. JACC Cardiovasc Interv. 2011;4:466-7.

6. von Birgelen C, Haude M, Erbel R. A word of caution on unrestricted use of synthetic stent grafts in native coronary arteries. Catheter Cardiovasc Interv. 2000;50:266-7.

7. Tyczynski P, Kukreja N, van Geuns RJ, Wykrzykowska JJ, Sheppard MN, Di Mario C. Optical coherence tomography for the assessment of pericardium covered stents for the treatment of degenerated saphenous vein grafts. EuroIntervention. 2010;6:78-85.

8. Süselbeck T, Haghi D, Borggrefe M, Kaden JJ. Percutaneous treatment of a coronary aneurysm by stent graft and drug-eluting stent implantation: a potential method to reduce stent graft restenosis. J Interv Cardiol. 2008;21:325-8.

9. Szalat A, Durst R, Cohen A, Lotan C. Use of polytetrafluoroethylene-covered stent for treatment of coronary artery aneurysm. Catheter Cardiovasc Interv. 2005;66:203-8.

10. Koo BK, Lee SP, Lee JH, Park KW, Suh JW, Cho YS, Chung WY, Doh JH, Nam CW, Yu CW, Lee BK, Vassilev D, Gil R, Lim HS, Tahk SJ, Kim HS. Assessment of clinical, electrocardiographic, and physiological relevance of diagonal branch in left anterior descending coronary artery bifurcation lesions. JACC Cardiovasc Interv. 2012;5:1126-32.

11. Win HK, Polsani V, Chang SM, Kleiman NS. Stent-assisted coil embolization of a large fusiform aneurysm of proximal anterior descending artery: novel treatment for coronary aneurysms. Circ Cardiovasc Interv. 2012;5:e3-5.

12. Terasawa A, Yokoi T, Kondo K. Stent-assisted coil embolization of coronary artery aneurysm. J Invasive Cardiol. 2013;25:E175-7.
13. Rekik S, Bernasconi F, Eker A, Appaix AB. Impressive progression of coronary artery disease assessed by serial multimodality imaging in a 40 year-old patient with Behçet's disease. Int J Cardiol. 2015;187:252-5.

14. Ebersberger U, Rieber J, Wellmann P, Goebel C, Gansera B. Polyarteritis nodosa causing a vast coronary artery aneurysm. $\mathrm{J} \mathrm{Am}$ Coll Cardiol. 2015;65:e1-2.

15. Crawley PD, Mahlow WJ, Huntsinger DR, Afiniwala S, Wortham DC. Giant coronary artery aneurysms: review and update. Tex Heart Inst J. 2014;41:603-8.

16. Boyer N, Gupta R, Schevchuck A, Hindnavis V, Maliske S, Sheldon M, Drachman D, Yeghiazarians Y. Coronary artery aneurysms in acute coronary syndrome: case series, review, and proposed management strategy. J Invasive Cardiol. 2014;26: 283-90.

17. Baman TS, Cole JH, Devireddy CM, Sperling LS. Risk factors and outcomes in patients with coronary artery aneurysms. Am J Cardiol. 2004;93:1549-51.

18. Murakami T, Tanaka N. The physiological significance of coronary aneurysms in Kawasaki disease. EuroIntervention. 2011;7:944-7.

19. Shaw LJ, Berman DS, Maron DJ, Mancini GB, Hayes SW, Hartigan PM, Weintraub WS, O'Rourke RA, Dada M, Spertus JA, Chaitman BR, Friedman J, Slomka P, Heller GV, Germano G, Gosselin G, Berger P, Kostuk WJ, Schwartz RG, Knudtson M, Veledar E, Bates ER, McCallister B, Teo KK, Boden WE; COURAGE Investigators. Optimal medical therapy with or without percutaneous coronary intervention to reduce ischemic burden: results from the Clinical Outcomes Utilizing Revascularization and Aggressive Drug Evaluation (COURAGE) trial nuclear substudy. Circulation. 2008;117:1283-91.

\section{Supplementary data}

Moving image 1. The first interlocking detachable coil embolisation through a microcatheter.

Moving image 2. TIMI 1 flow in D1 after the coil embolisation procedure. 